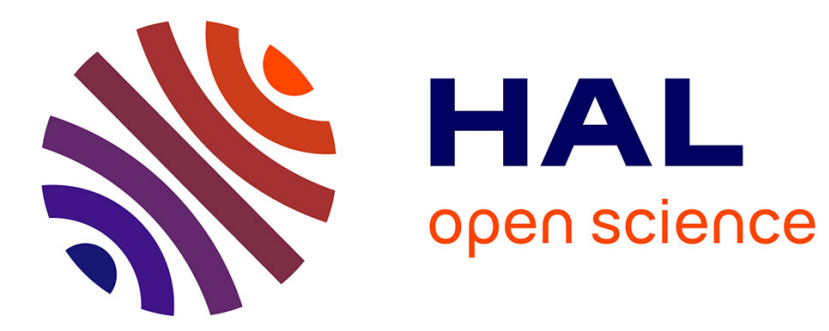

\title{
DESIGN OPTIMIZATION IN ELECTROSTATIC-FIELD ANALYSIS USING THE BEM AND THE AUGMENTED LAGRANGIAN METHOD
}

Joao Antonio Vasconcelos, Laurent Krähenbühl, Laurent Nicolas, Alain Nicolas

\section{To cite this version:}

Joao Antonio Vasconcelos, Laurent Krähenbühl, Laurent Nicolas, Alain Nicolas. DESIGN OPTIMIZATION IN ELECTROSTATIC-FIELD ANALYSIS USING THE BEM AND THE AUGMENTED LAGRANGIAN METHOD. IEEE Transactions on Magnetics, 1994, 30 (5) (5 Part 2), pp.3443-3446. hal-00140687

\section{HAL Id: hal-00140687 https://hal.science/hal-00140687}

Submitted on 25 Apr 2007

HAL is a multi-disciplinary open access archive for the deposit and dissemination of scientific research documents, whether they are published or not. The documents may come from teaching and research institutions in France or abroad, or from public or private research centers.
L'archive ouverte pluridisciplinaire HAL, est destinée au dépôt et à la diffusion de documents scientifiques de niveau recherche, publiés ou non, émanant des établissements d'enseignement et de recherche français ou étrangers, des laboratoires publics ou privés. 


\title{
Design Optimization in Electrostatic Field Analysis Using the BEM and the Augmented Lagrangian Method
}

\author{
J. A. Vasconcelos (*) L. Krähenbühl L. Nicolas A. Nicolas \\ Centre de Génie Electrique de Lyon - URA CNRS 829 \\ Ecole Centrale de Lyon \\ BP163 - 69131 Ecully Cedex - France \\ (*) Electrical Engineering Department - UFMG - Brazil
}

\begin{abstract}
The aim of this paper is to discuss the reliability of a new algorithm based on the augmented Lagrangian method (ALM) coupled with the boundary element method (BEM) for design optimization in electromagnetics. These methods, implemented as a computer code, have been applied for the solution of electrostatic problems. Two analytical problems are considered and the convergence of the ALM for different starting points has been noted. Also, the algorithm is robust with respect to the number of design variables. Moreover, two electrostatic problems have been solved and the efficiency of the ALM coupled with the BEM has been observed.
\end{abstract}

\section{INTRODUCTION}

Recently, the application of electromagnetic field analysis coupled with optimization methods to solve inverse problems has been of increasing interest. Numerical methods such as the finite element method (FEM) and the boundary element method for field analysis and an optimization method based either on a deterministic or stochastic approach have been used. The choice of the best algorithm to be used depends on several factors, such as the objective function complexity and the number of design parameters.

The BEM possesses certain characteristics, such as the discretization only of the boundary, the facility with which infinite boundaries can be represented and the high accuracy in potential and flux results, that make it appropriate to be used for electrostatic optimization problems

According to Bellina et al., the stochastic methods, especially that of the simulated annealing, are attractive when the objective function evaluation is fast and the number of design parameters is large. These methods give a good approximation of the global minimum. In the other cases, these methods are expensive in time [1].

Usually, in design optimization in electromagnetics the objective function is constructed as a function of the flux, requiring its evaluation either by BEM or FEM. The number of field calculations is thus a very important factor to be considered when choosing an algorithm.

In the last two years, some papers have been dedicated to the study of the augmented Lagrangian methods, also called the multiplier methods [2], [3]. These methods solve the problem by minimizing a sequence of unconstrained problems defined using the objective and constraint functions. However, these methods have a special structure that make them well-suited for handling large optimization problems. This special feature is that all implicit constraint functions are collapsed into a transformation function $\Phi$ whose gradient computation involves only one set of backsubstitutions. Also, the active set strategy offered by the ALM can be highly useful when the number of constraints is quite large.

In this paper, the ALM coupled with the BEM for optimization in electrostatics is presented.

\section{THE BOUNDARY ELEMENT METHOD FORMULATION}

The electrostatic field problem in the absence of a volume charge distribution is represented by the following Laplace equation:

$$
\nabla^{2} \mathbf{u}=0
$$

where $\underline{u}$ is the electrostatic potential. The boundary element formulation for (1) using Green's theorem gives:

$$
C u=\int_{1}\left(q^{*} u-u^{*} q\right) d l
$$

where $\mathrm{g}$ is the normal derivative of $\underline{\underline{u}}, \underline{u}^{*}$ is the fundamental solution, $\mathrm{q}^{*}$ the normal derivative of this fundamental solution and $\mathrm{C}$, a constant.

The equation system obtained by applying (2), after the discretization of the boundary, the substitution of the boundary conditions and separating the unknown and known variables is given in (3).

$$
[\mathrm{A}]\{\mathrm{x}\}=\{\mathrm{b}\}
$$

In (3), $[A]$ is the coefficient matrix, $\{x\}$ is a vector of unknown values of potential and flux on the boundaries and $\{b\}$ is an independent vector.

\section{The Augmented LAGRANGIAN METHOD}

The constrained non-linear optimization problem can be expressed as:

$$
\begin{array}{lll}
\min & f(p) & \\
\text { with } & g_{i}(p)=0 & i=1,1 \\
& g_{i}(p) \leq 0 & i=1+1, m
\end{array}
$$


where $f(p)$ and $g_{i}(p)$ are the objective and the $i$-th constraint function and $p$ is a vector of design variables.

In the ALM, all functions in (4) are collapsed into a single transformation function $\Phi$, also called the augmented Lagrangian. This function is given in [4] as:

$$
\Phi(\mathbf{p}, \mathbf{r}, \theta)=\mathbf{f}(\mathbf{p})+\frac{1}{2} \sum_{\mathrm{i}=1}^{1} \mathbf{r}_{\mathrm{i}}\left(\mathrm{g}_{\mathrm{i}}+\theta_{\mathrm{i}}\right)^{2}+\frac{1}{2} \sum_{\mathrm{i}=1+1}^{\mathrm{m}} \mathbf{r}_{\mathrm{i}}\left(\mathrm{g}_{\mathrm{i}}+\theta_{\mathrm{i}}\right)_{+}^{2}
$$

Above, $r$ is a vector of penalty parameters and $\mu_{i}=r_{i} \theta_{i}$ is the Lagrange multiplier associated with the $i$-th constraint. Values of $\mathbf{r}$ and $\theta$ are chosen at the beginning of the optimization process and at the end of each unconstrained minimization they are updated and the process repeated until convergence.

The original problem is replaced by a sequence of unconstrained subproblems that need to be solved at each iteration. The subproblem at the $\mathrm{j}$-th iteration can be written as follows:

$$
\begin{gathered}
\min \Phi\left(\mathrm{p}, \mathrm{r}^{\mathrm{j}}, \theta^{\mathrm{j}}\right) \\
\mathrm{p}_{\mathrm{k}_{\min }} \leq \mathrm{p}_{\mathrm{k}} \leq \mathrm{p}_{\mathrm{k}_{\text {max }}}
\end{gathered}
$$

To solve the unconstrained subproblem, a method minimizing a quadratic approximation to $\Phi$ is used. This method is derived from Taylor series, and limits the change in the design to lie within a certain region of trust. It is known as the trust region method [5].

\section{OPTIMLZATION IN ELECTROSTATICS}

To discuss optimization in electrostatics the following objective function is considered:

$$
\mathbf{f}(p)=\frac{1}{2} \sum_{j=1}^{n}\left(E_{j}-E_{o j}\right)^{2}
$$

where $E_{j}$ and $E_{o j}$ are respectively the computed and the specified normal electric fields at testing point $j$.

The total derivative of the objective function with respect to the $k$-th design variable $p_{k}$ can be written as:

$$
\frac{\mathrm{df}}{\mathrm{dp}_{\mathrm{k}}}=\frac{\partial \mathrm{f}}{\partial \mathrm{p}_{\mathrm{k}}}+\frac{\partial \mathrm{f}}{\partial\{\mathrm{x}\}} \frac{\partial\{\mathrm{x}\}}{\partial \mathrm{p}_{\mathrm{k}}}
$$

where the last derivative on the right hand side may be found from differentiating (3):

$$
\mathrm{A} \frac{\partial\{\mathbf{x}\}}{\partial \mathbf{p}_{\mathrm{k}}}=\frac{\partial\{\mathrm{b}\}}{\partial \mathrm{p}_{\mathrm{k}}}-\frac{\partial[\mathrm{A}]}{\partial \mathrm{p}_{\mathrm{k}}}\{\mathrm{x}\}
$$

By solving (9) for each design variable the gradient of the objective function can be obtained. If any constraint is a function of the flux, its gradient can also be calculated.

\section{ANALYTICAL RESULTS}

A computer code based on the ALM was developed and it has been tested using two test problems: the Rosen-Suzuki problem [3] and that one given by the minimization of the Rosenbrock's function $f_{2}$ (Fig. 1) [6].

The first problem is a non-linear constraint minimization problem of four design variables $\mathrm{p}=\left(\mathrm{p}_{1}, \mathrm{p}_{2}, \mathrm{p}_{3}, \mathrm{p}_{4}\right)^{\mathrm{T}}$ and three constraint functions, as shown in (10).

$$
\begin{aligned}
& \min f_{1}(p)=p_{1}^{2}+p_{2}^{2}+2 p_{3}^{2}+p_{4}^{2}-5 p_{1}-21 p_{3}+7 p_{4}+100 \\
& \text { with } g_{1}(p)=p_{1}^{2}+p_{2}^{2}+p_{3}^{2}+p_{4}^{2}+p_{1}-p_{2}+p_{3}-p_{4}-8 \leq 0 \\
& g_{2}(p)=p_{1}^{2}+2 p_{2}^{2}+p_{3}^{2}+2 p_{4}^{2}-p_{1}-p_{4}-10 \leq 0 \\
& g_{3}(p)=2 p_{1}^{2}+p_{2}^{2}+p_{3}^{2}+2 p_{1}-p_{2}-p_{4}-5 \leq 0
\end{aligned}
$$

The optimum objective function value for this problem is $f_{1}\left(p^{*}\right)=56$ with the optimal design $p^{*}=(0,1,2,-1)^{\mathrm{T}}$. At $p^{*}$ the constraints 1 and 3 are active.

In the second problem, a non-linear function of two variables $p=\left(p_{1}, p_{2}\right)^{T}$ is to be optimized. This function is given by (11). It is obvious that this function has a optimum in $\mathrm{p}^{*}=(1,1)$ with $\mathrm{f}_{2}\left(\mathrm{p}^{*}\right)=0.0$.

$$
\begin{aligned}
& \min f_{2}(p)=100\left(p_{1}^{2}-p_{2}\right)^{2}+\left(1-p_{1}\right)^{2} \\
& -2.048 \leq p_{k} \leq 2.048 \quad k=1,2
\end{aligned}
$$

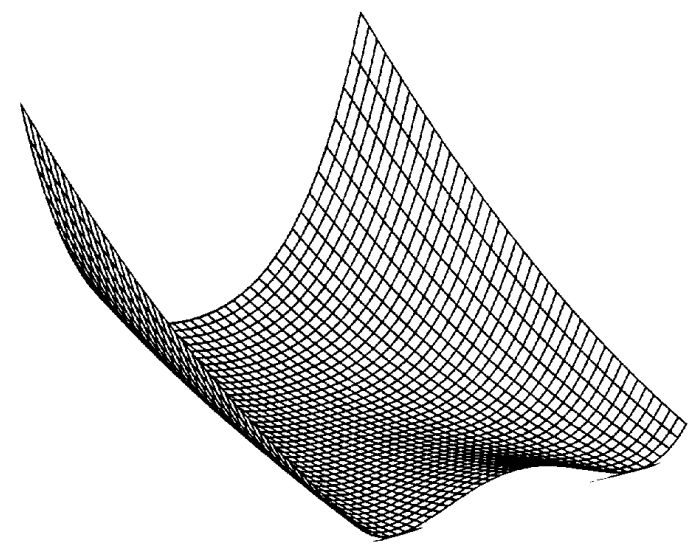

Fig. 1 Rosenbrock's function $f_{2}(p)$ 
TABLE I

ROSEN-SUZUKI PROBLEM

\begin{tabular}{rrrrr}
\hline $\mathrm{p}_{1}$ & 0.0000 & 3.0000 & 3.0000 & -4.0000 \\
$\mathrm{p}_{2}$ & 0.0000 & -3.0000 & 3.0000 & -2.0000 \\
$\mathrm{p}_{3}$ & 0.0000 & 0.0000 & 3.0000 & 2.0000 \\
$\mathrm{p}_{4}$ & 0.0000 & 5.0000 & 3.0000 & 4.0000 \\
\hline $\mathrm{f}_{2}$ & 100.0000 & 178.0000 & 73.0000 & 160.0000 \\
\hline $\mathrm{p}_{1}{ }^{*}$ & 0.0002 & -0.0020 & -0.0015 & -0.0015 \\
$\mathrm{p}_{2}{ }^{*}$ & 0.9998 & 0.9991 & 1.0005 & 1.0024 \\
$\mathrm{p}_{3}{ }^{*}$ & 2.0000 & 1.9993 & 2.0009 & 2.0042 \\
$\mathrm{p}_{4}{ }^{*}$ & -1.0000 & -1.0021 & -0.9988 & -0.9837 \\
\hline $\mathrm{f}_{2}{ }^{*}$ & 56.0002 & 56.0111 & 56.0000 & 56.0273 \\
\hline nbcal & 69 & 127 & 82 & 76 \\
\hline
\end{tabular}

TABLE II

ROSENBROCK'S FUNCTION F 2 .

\begin{tabular}{crrrr}
\hline $\mathrm{p}_{1}$ & 0.0000 & 1.0000 & -1.0000 & 2.0000 \\
$\mathrm{p}_{2}$ & 0.0000 & 0.0000 & 1.0000 & -2.0000 \\
\hline $\mathrm{f}_{2}$ & 1.0000 & 100.0000 & 4.0000 & 3601.0000 \\
\hline $\mathrm{p}_{1}{ }^{*}$ & 1.0014 & 1.0089 & 0.9885 & 1.0052 \\
$\mathrm{p}_{2}{ }^{*}$ & 1.0027 & 1.0174 & 0.9769 & 1.0101 \\
\hline $\mathrm{f}_{2}{ }_{\text {nbcal }}$ & 0.0000 & 0.0001 & 0.0001 & 0.0000 \\
\hline
\end{tabular}

Several computations using different starting points were made. The results are shown in Table I and II, where nbcal is the number of objective function calculation. The ALM perform well for all tested points.

\section{Electrostatic Problems}

The code that implements the BEM in conjunction with the ALM is named BEM2D [7]. Two electrostatic optimization problems were chosen to illustrate its application. The first problem to optimize is the design of the lower corner of the uniform square plates, as shown in Fig. 2, and in the second, the design of the HV electrode of the insulator shown in Fig. 5 is to be optimized.

The first problem was optimized using the following objective function:

$$
\begin{aligned}
& \min f(p)=\sum_{j=1}^{n}\left(E_{j}^{2}-E_{o j}^{2}\right)^{2} \\
& \mathrm{p}_{\mathrm{k}_{\text {min }}} \leq \mathrm{p}_{\mathrm{k}} \leq \mathrm{p}_{\mathrm{k}_{\max }} \quad \mathrm{k}=1, \ldots, \mathrm{nv}
\end{aligned}
$$

where $p_{k}$ is the distance of the $k$-th point on the movable boundary (Fig. 2), either $E_{j}$ and $E_{o j}$ are the calculated and desired normal electric field values at the $j$-th test point, also on the movable boundary. The number of design variables nv was made equal to $11, \mathrm{E}_{\mathrm{oj}}$ was kept equal to $1.2 \mathrm{~V} / \mathrm{m}$ for all testing point $j$ and the bounds $p_{k m i n}$ and $p_{k \max }$ were made equals to 0.936 and $1.144 \mathrm{~m}$ respectively. It can be seen that the initial design is not feasible.
Fig. 3 displays the normal electric field values at the test points on the movable boundary, before and after the optimization. As can be seen, the optimization process start with an "infinite" value for the electric field on the lower corner to obtain a quasi-uniform electric field distribution.

The boundary evolution during the optimization process is shown in Fig. 4.

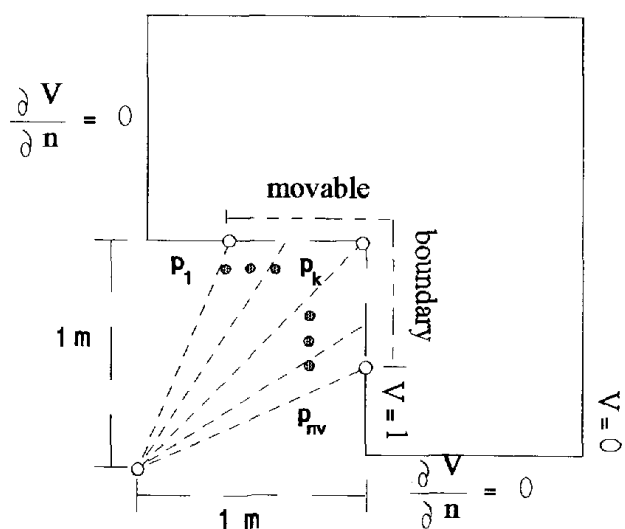

Fig. 2 Uniform square plate geometry with the design variables and the boundary conditions.

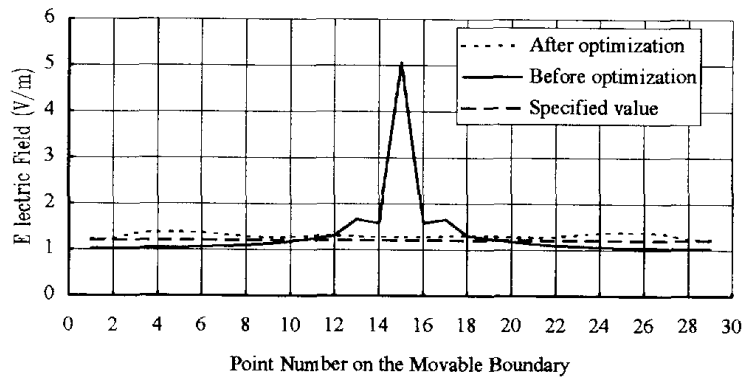

Fig. 3 Electric field at the test points on the movable boundary.

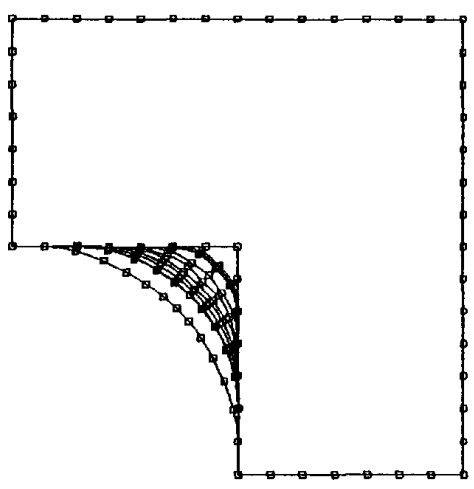

Fig. 4 The boundary evolution during the optimization process.

The second problem to be optimized is an insulator that has been used to test differents softwares of electrostatic field calculation [8]. The goal is to achieve a maximum normal electric field equal to $30 \mathrm{~V} / \mathrm{m}$ in the region of 
interest. Five design variables $p=\left(p_{1}, p_{2}, p_{3}, p_{4}, p_{5}\right)^{T}$, which shall be optimized, are indicated in Fig. 5. The boundary conditions were made equals to 1 and $0 \mathrm{~V}$ on the higher and lower electrodes respectively.

The following objective function was employed to solve this problem:

$$
\begin{array}{ll}
\min & \mathrm{f}(\mathrm{p})=\left(\mathrm{E}_{\max }^{2}-\mathrm{E}_{\mathrm{o}}^{2}\right)^{2} \\
\text { with } & \mathrm{g}(\mathrm{p})=\mathrm{E}_{\max }^{2}-\left(\mathrm{E}_{\mathrm{o}_{\min }}+\mathrm{E}_{\mathrm{o}_{\max }}\right) \mathrm{E}_{\max }+\mathrm{E}_{\mathrm{o}_{\min }} \mathrm{E}_{\mathrm{o}_{\max }} \leq 0 \\
& \mathrm{p}_{\mathrm{k}_{\min }} \leq \mathrm{p}_{\mathrm{k}} \leq \mathrm{p}_{\mathrm{k}_{\max }} \quad \mathrm{k}=1, \ldots, \mathrm{nv}
\end{array}
$$

where $E_{\max }$ is the maximum normal electric field found among all testing points on the movable boundary, $E_{o}$ is the desired maximum normal electric field on the region of interest and either $E_{\text {omin }}$ and $E_{\text {omax }}$ are the inferior and superior bounds for the normal electric field in the constraint function $g(p)$. Above, $\mathrm{E}_{\text {omin }}$ and $\mathrm{E}_{\mathrm{omax}}$ were made equals to 0.0 and $30.03 \mathrm{~V} / \mathrm{m}$ respectively.

The results are schematically shown in Table III and the normal electric field before and after the optimization process on the higher electrode is displayed in Fig. 6. The maximum normal electric field values found before and after the optimization were 41.54 and $29.997 \mathrm{~V} / \mathrm{m}$ respectively.
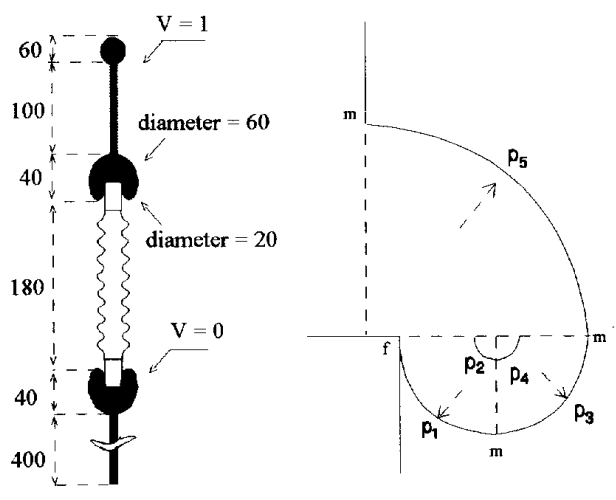

Fig. 5 Insulator (left) and a zoom of the boundary to be optimized showing the five design parameters $\left(p_{1}, \ldots, p_{5}\right)$, where $f$ denotes a fixed point and $m$ a mobile point (right).

TABLE III

INITIAL AND FINAL DESIGN VARIABLE VALUES.

\begin{tabular}{lcc}
\hline Design variables & Initial geometry & Optimized geometry \\
\hline $\mathrm{p}_{1}(\mathrm{~mm})$ & 10.0 & 19.4 \\
$\mathrm{p}_{2}$ (degree) & -90.0 & -90.0 \\
$\mathrm{p}_{3}(\mathrm{~mm})$ & 10.0 & 15.8 \\
$\mathrm{p}_{4}($ degree $)$ & 0.0 & 0.0 \\
$\mathrm{p}_{5}(\mathrm{~mm})$ & 30.0 & 30.5 \\
\hline $\mathrm{E}_{\max }(\mathrm{V} / \mathrm{m})$ & 41.54 & 29.997 \\
\hline
\end{tabular}

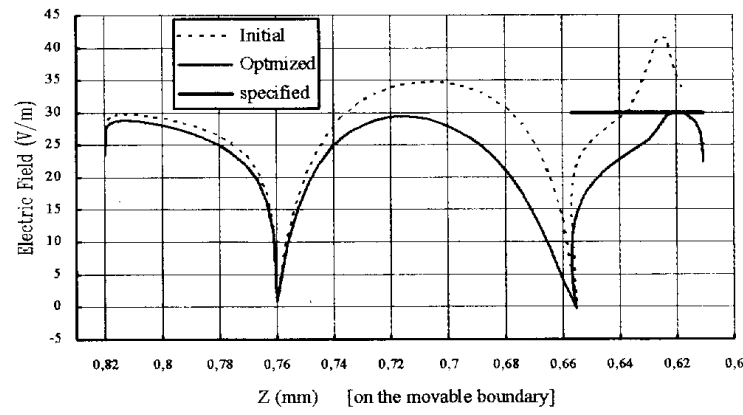

Fig. 6 Normal electric field on the higher electrode.

The result obtained represents a gain of $27.8 \%$ on the maximum normal electric field, which can be considered as very good result.

\section{CONCLUSION}

The augmented Lagrangian method coupled with the boundary element method to solve optimization problems in electrostatics was presented in this paper. The results obtained in the solution of the two test problems show that the ALM is reliable and robust with respect to the number of design variables as well as with respect to different starting points. Its performance is very attractive. Only nine field calculations were executed in the insulator optimization. The solution of the electrostatic problems shows that the ALM-BEM works well and the optimization of electrostatic devices offers no problems.

\section{REFERENCES}

[1] F. Bellina, P. Campostrini, G. Chitarin, A. Stella and F. Trevisan, "Automated optimal design techniques for inverse electromagnetic problems", IEEE Trans. on Magnetics, vol. 28, No 2, pp. 1549-1552, March 1992.

[2] J. S. Arora, A. I. Chahande and J. K. Paeng, "Multiplier methods for engineering optimization", Int. J. for Num. Meth. Eng., vol. 32, pp. 1485$1525,1991$.

[3] M. Sunar and A. D. Belegundu, "Trust region methods for structural optimization using exact second order sensitivity", Int. J. for Num. Meth. Eng., vol. 32, pp. 275-293, 1991.

[4] R. Fletcher, "An ideal penalty function for constrained optimization", J. Inst. Math. Optimization, vol. 15, pp. 319-342, 1975

[5] R. Fletcher, "Practical Methods of Optimization, vol. 1, Unconstrained Optimization", John Wiley, New York, 1980.

[6] C. A. Magele, K. Preis, W. Renhart, R. Dyczij-Edlinger and K. R. Richter, "Higher order evolution strategies for the global optimization of electromagnetic devices", IEEE Trans. on Magnetics, vol. 29, No 2, pp. 1775-1778, March 1992.

[7] J. A. Vasconcelos, L. Nicolas and F. Buret, "Shape optimization of an HV connector in GIS", unpublished.

[8] R. Parraud, "Mesures et calculs comparatifs du champ électrique sur des isolateurs haute tension", Electra No 141, pp. 68-77, April 1992. 